\title{
Peertechz
}

\section{Non-Opioid Otolaryngology Medical Practice}

\author{
Samba Siva Reddy Bathula* and Dustin Jones DO \\ Department of Otolaryngology, Head and Neck Surgery, Detroit Medical Center, Detroit, MI, USA
}

Received: 11 July, 2020

Accepted: 27 July, 2020

Published: 28 July, 2020

*Corresponding author: Samba Siva R Bathula, MD, Department of Otolaryngology, Head \& Neck Surgery, Detroit Medical Center, Detroit, MI-48201, USA, Clinic No: 313-966-9471; E-mail: sambasivareddy@yahoo.com

Keywords: Non-Opioid pain management; NSAID; Postoperative pain medications

https://www.peertechz.com

Check for updates

\begin{abstract}
Introduction: Opioids have been used as pain medications in the United States since the late 1990s and have become increasingly common since then. Following the declaration of a public health emergency by the US Department of Health and Human Services (US-HHS), the author switched from opioid-based pain management to non-opioid-based pain management without any significant pain concerns from his postoperative patients. The primary purpose of this article was to demonstrate how much opioids in morphine milligram equivalents (MME) was prescribed per month by the author according to Michigan Prescription Monitoring Program (PMP) Prescriber Activity Reports before and after 2018 for management of pain in his otolaryngology postoperative surgical patients.
\end{abstract}

Methods: A retrospective research methodology was employed for this investigation. Michigan PMP Prescriber Reports were collected before and after 2018 and were included in this study.

Results: The author prescribed opioid pain medications before the HHS declaration. After the HHS declaration, the author prescribes acetaminophen and Nonsteroidal Anti-Inflammatory Drugs (NSAIDs). The number of opioid prescriptions from the author were remarkably low compared to similar prescribers and others within the author's specialty.

Prescription by MME showed no notable difference in MME values from 0-50 before and after the HHS declaration among the author and SP groups, but a notable drop of MME values from 51-90 among all groups after the HHS declaration.

Discussion: The author discourages the use of opioid pain medications for routine otolaryngology procedures. This study demonstrates the effective use of acetaminophen with or without NSAIDs (ibuprofen and diclofenac) to facilitate patient care absent of the well-established dangers of opioid use.

\section{Introduction}

Opioids have been used as pain medications in the United States since the late 1990s. Since then, opioid pain medication prescriptions increased exponentially after pharmaceutical companies informed medical practitioners that opioids were not addictive pain medications. There have been 42,000 deaths related to opioid overdoses in 2016 in the US, and $40 \%$ of the opioid overdose deaths involved prescription opioids [1]. Based on a significant number of opioid-related deaths, the US Department of Health and Human Services (HHS) declared a public health emergency and announced a fivepoint strategy to combat the opioid crisis on October 26, 2017 [2]. As an otolaryngologist, the author previously prescribed a remarkable amount of opioids for his patients' postoperative pain management. After the HHS declaration, the author switched from opioids to non-opioids without any notable reported pain concerns from his postoperative patients [3].
The primary purpose of this article was to demonstrate how much narcotic in Morphine Milligram Equivalents (MME) was prescribed per month by the author according to Michigan Prescription Monitoring Program (PMP) Prescriber Activity Reports (PAR) before and after 2018 for management of pain in his otolaryngology postoperative surgical patients. The author intends to actively discourage the use of opioid pain medications for routine otolaryngology procedures and to instead use acetaminophen with or without Nonsteroidal AntiInflammatory Drugs (NSAIDs) to improve patient care.

\section{Material and methods}

This retrospective review and analysis included reviewing the state of Michigan's Prescription Monitoring Programs (PMP) prescriber activity reports (PAR) spanning January $1^{\text {st }}$ 2017 to December $31^{\text {st }} 2019$. The inclusion criteria was defined as all PMP reports spanning the aforementioned time frame. No PMP reports were excluded from the review and the study 
was deemed to be Institutional Review Board (IRB) except by not including patient specific information. t-Test: TwoSample Assuming Unequal Variances statistical method was used to analyze the data and notable findings were highlighted in table format in the following sections.

The author of this paper is referred to as the primary author. The term similar prescriber (SP) is defined as a prescriber that has the same role (e.g., physician, dentist, nurse practitioner) and the same healthcare specialty (e.g., internal medicine, pain management, oncology).

The author's pain medication regimens are as follows Prior to 2018 and the HHS declaration, the author primarily prescribed one of the following pain regimens: Tylenol with Codeine \#3 (acetaminophen $300 \mathrm{mg} /$ codeine phosphate $30 \mathrm{mg}$ ) every six hours, Norco (hydrocodone and acetaminophen at $5.0 / 325,7.5 / 325$, or $10 / 325 \mathrm{mg}$ ) every six hours, or tramadol. After 2018 and the HHS declaration, the author shifted to prescribing either acetaminophen (500 $\mathrm{mg}$ ) every six hours, for five to 10 days and diclofenac ( $50 \mathrm{mg}$ ) every 12 hours for five days, or ibuprofen $(600 \mathrm{mg})$ three times daily for five days.

The primary endpoints of this investigation were two-fold: (1) to identify and quantify the monthly narcotic prescribing patterns in MME preceding and following the implementation of the HHS based on the PMP PAR. (2) Compare and contrast this to Similar Prescribers (SP) meeting the same criteria described in the aforementioned fashion.

\section{Results}

Table 1 depicts narcotic prescriptions before and after 2018 resulting in 16.45 prescriptions per month relative to 6.9 prescriptions per month by SP within the same specialty $(\mathrm{p}=3.7)$. Following the HHS declaration, the author's narcotic prescriptions were remarkably lower relative to the SP group $(1.5 ; 10.16)(\mathrm{p}=1.8)$.

When looking at prescriptions by MME (Table 2). No notable difference were found in MME values from $0-50$ before and after the HHS declaration among the author and SP groups. However, a notable decrease, although, not statistically significant $(\mathrm{p}=1.79)$ in MME for values in the 51-90 range among all groups after the HHS declaration.

Opioid treatment duration is outlined in Table 3. Prior to 2018 , the authors mean prescriptions were 6.29 compared to 55.54 prescriptions from SP's $(p=2.49)$. Following the HHS declaration, the author's prescriptions for longer than seven days significantly dropped (90; 84.02); compated to SP's. Prescriptions for fewer than seven days went up for all two groups after the HHS declaration.

The author prescribed a notable amount of oxycodone and hydrocodone medications prior to the HHS declaration. The number of these prescriptions dropped notably after the HHS declaration, as shown in Table 4. At the same time, no notable change in opioid prescriptions in the SP group were seen even after the HHS declaration. There was no remarkable change in number of authors surgical procedures even after the HHS declaration, as illustrated in Figure 1.
Table 1: Comparison of opioid prescriptions written per month before and after 2018

\begin{tabular}{|c|c|c|c|}
\hline \multirow{2}{*}{ Comparator } & \multicolumn{3}{|c|}{ Mean opioid prescriptions written per month } \\
\cline { 2 - 4 } & author & similar prescriber & P value \\
\cline { 2 - 4 } & mean & mean & \\
\hline Before 2018 & 16.45 & 6.9 & 3.7 \\
\hline After 2018 & 1.5 & 10.16 & 1.8 \\
\hline
\end{tabular}

Table 2: Comparison of prescription by MME percentage before and after 2018 .

\begin{tabular}{|c|c|c|c|c|}
\hline \multirow{2}{*}{ MME Range } & Comparator & \multicolumn{3}{|c|}{ MME (\%) } \\
\cline { 3 - 5 } & & Author Mean & SP Mean & P value \\
\hline \multirow{2}{*}{ MME 0-50 } & Before 2018 & 95.94 & 79.92 & 4.83 \\
\cline { 3 - 5 } & After 2018 & 85.83 & 92.28 & 0.003 \\
\hline \multirow{2}{*}{ MME 51-90 } & Before 2018 & 4.05 & 19.44 & 6.66 \\
\hline & After 2018 & 14.16 & 7.3 & 1.79 \\
\hline
\end{tabular}

Table 3: Comparison of opioid treatment duration before and after 2018.

\begin{tabular}{|c|c|c|c|c|}
\hline \multirow{2}{*}{ Duration } & Comparator & \multicolumn{3}{|c|}{ Opioid treatment duration (\% patients) } \\
\cline { 3 - 5 } & Author Mean & SP mean & P value \\
\hline \multirow{2}{*}{$<7$ days } & Before 2018 & 6.29 & 55.54 & 2.49 \\
\cline { 2 - 5 } & After 2018 & 90 & 84.02 & 0.07 \\
\hline \multirow{2}{*}{$7-28$ days } & Before 2018 & 48.63 & 37.74 & 2.16 \\
\cline { 2 - 5 } & After 2018 & 10 & 15.01 & 0.13 \\
\hline \multirow{2}{*}{$29-90$ days } & Before 2018 & 34.28 & 5.67 & 4.14 \\
\cline { 2 - 5 } & After 2018 & 0 & 0.85 & 1.89 \\
\hline \multirow{2}{*}{$>90$ days } & Before 2018 & 10.78 & 1.04 & 1.75 \\
\hline & After 2018 & 0 & 0.12 & 9.78 \\
\hline \multirow{2}{*}{ Abbreviations: SP: Similar Prescriber } & & & \\
\hline
\end{tabular}

Abbreviations: SP: Similar Prescriber

Table 4: Comparison of mean MME by product prescribed per month before and after 2018.

\begin{tabular}{|c|c|c|c|c|}
\hline \multirow{2}{*}{ Product type } & \multirow{2}{*}{ Comparator } & \multicolumn{3}{|c|}{ Mean MME prescriptions per month } \\
\cline { 3 - 5 } & & Author mean & SP mean & P value \\
\hline \multirow{2}{*}{ Oxycodone products } & Before 2018 & 1162.5 & 22 & 1.80 \\
\cline { 2 - 5 } & After 2018 & 0 & 81 & 5.62 \\
\hline \multirow{2}{*}{ Hydrocodone products } & Before 2018 & 9621 & 913 & 1.62 \\
\cline { 2 - 5 } & After 2018 & 137 & 1200.5 & 2.12 \\
\hline \multirow{2}{*}{ Other opioids } & Before 2018 & 657 & 105.5 & 2.59 \\
\cline { 2 - 5 } & After 2018 & 71 & 202 & 3.7 \\
\hline
\end{tabular}

Abbreviations: MME: Morphine Milligram Equivalents; SP: Similar Prescriber

\section{Number of Otolaryngology procedures}

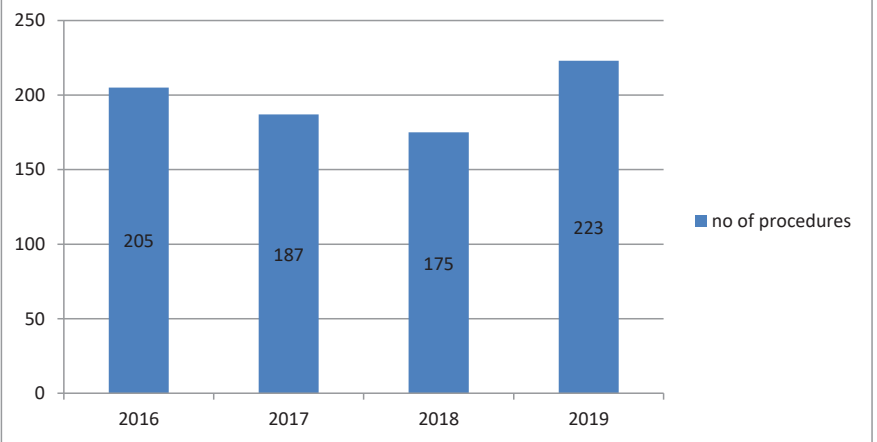

Figure 1: Number of Otolaryngology procedures.

\section{Discussion}

Management of perioperative pain is a medical conundrum and misuse or improper narcotic prescribing has been lead to prolonged rehabilitation, development of chronic pain, and reduced quality of life scales $[4,5]$. The effectiveness of 
opium's ability to ameliorate pain has been used for decades. Opioids trigger a release of dopamine, stimulating the brain by occupying pain receptors. This leads to a cascade of receptor downregulation and an initial feeling of euphoria for patients prior to the amelioration of pain. The opioid epidemic is a serious health problem in the US at present. Overdoses caused more than 47,000 deaths in 2017 , and $36 \%$ of those deaths involved prescription opioids [1]. On average, 130 Americans die every day from an opioid overdose [6]. In lieu of opioid addiction, Physicians around the world used different combinations of nonopioid medications to manage postoperative pain. Reduction of opioid requirements and better postoperative analgesia with less adverse effects were noticed when addition of NSAIDs and/or acetaminophen to opioid for postoperative pain management [7-9].

The aforementioned sections comprehensively demonstrated that the author previously wrote an abundance of opioids for his otolaryngology postoperative patients. Following the advent of the HHS declaration, the author switched from opioid pain medications to non-opioid pain medications, including acetaminophen, ibuprofen, and diclofenac for most routine otolaryngology surgical patients.

Combinations of acetaminophen and an NSAID have been thoroughly described In the literature and may offer superior analgesia relative to either drug alone in acute postoperative pain management without opioid use [10-12].

The author is a general otolaryngologist at an academic institute and performs routine general otolaryngology surgeries such as adenotonsillectomy, micro laryngeal surgery, ear tubes, septoplasty, bilateral inferior turbinate reduction, functional endoscopic sinus surgery, parotidectomy, submandibular gland excision, thyroidectomy, parathyroidectomy, tracheostomy, and neck mass excision including neck dissections.

The author did not notice any remarkable uncontrolled postoperative pain concerns from surgical patients after switching to non-opioid pain medications, which explain why his narcotic prescriptions were significantly lower in the PMP report after 2018. Additionally, the author performed almost the same number of surgeries mentioned above before and after 2018. At present, the author is prescribing opioid pain medications only to renal and head-neck malignancy patients.

After analysis, it was noted that the PMP reports indicate the SP group was still prescribing a large amount of opioid pain medications. It was also noted in a recently published article that opioids remained the primary modality for postoperative tonsillectomy pain management [13]. If ear-nose-throat surgeons keep prescribing narcotic pain medications, we are not helping society to curb the opioid epidemic. The main intention of this paper is to discourage the use of opioid pain medications for routine otolaryngology procedures and instead encourage the use of acetaminophen and NSAIDs to improve patient care.

Study limitations include the retrospective nature of this quality improvement and the small sample size of including one author's Michigan. PMP reports before and after 2018 and his clinical experience. Additionally, Visual Acuity Scales and validated quality of life scales were not assessed. The author did not compare Acetaminophen and nonsteroidal antiinflammatory drugs between the patient before or after 2018 . Multi-center, randomized, prospective controlled trials on acetaminophen and NSAID pain medication use in these cases are needed.

\section{Conclusion}

The opioid epidemic is causing significant mortality in the US; most of this originates from prescription opioids. The author discourages the use of Opioid pain medications for routine otolaryngology procedures and herein demonstrates the effective use of acetaminophen with or without NSAIDs (ibuprofen and diclofenac) to improve patient care.

\section{References}

1. Scholl L, Seth P, Kariisa M, Wilson N, Baldwin G (2019) Drug and Opioid Involved Overdose Deaths - United States, 2013-2017. MMWR Morb Mortal Wkly Rep 67: 1419-1427. Link: https://bit.ly/2EnxI5P

2. US Department of Health and Human Services (2017) HHS Acting Secretary Declares Public Health Emergency to Address National Opioid Crisis. Link: https://bit.ly/2P1gWpN

3. Bathula Samba SR, Noah S, Dworkin-Valenti James P (2020) Adult posttonsillectomy pain management: Opioid versus non-opioid drug comparisons. Arch Otolaryngol Rhinol 6: 041-048. Link: https://bit.ly/3g5XiEV

4. Kehlet H, Holte K (2001) Effect of postoperative analgesia on surgical outcome. Br J Anaesth 87: 62-72. Link: https://bit.ly/2CT1qda

5. Kehlet H, Jensen TS, Woolf CJ (2006) Persistent postsurgical pain: risk factors and prevention. Lancet (London, England). 367: 1618-1625. Link: https://bit.ly/306N7dC

6. Centers for Disease Control and Prevention (2017) National Center for Health Statistics: Wide-ranging online data for epidemiologic research (WONDER). Atlanta, GA. Link: https://bit.ly/3g9MDcC

7. Wong I, St John-Green C, Walker SM (2013) Opioid-sparing effects of perioperative paracetamol and nonsteroidal anti-inflammatory drugs (NSAIDs) in children. Paediatr Anaesth 23: 475-495. Link: https://bit.ly/2P7PjLD

8. McDaid C, Maund E, Rice S, Wright K, Jenkins B, et al. (2003) Paracetamo and selective and non-selective non-steroidal anti-inflammatory drugs (NSAIDs) for the reduction of morphine-related side effects after major surgery: a systematic review. 2010. In: NIHR Health Technology Assessment programme: Executive Summaries. Southampton (UK): NIHR Journals Library. Link: https://bit.ly/2CTDuGC

9. Elia N, Lysakowski C, Martin R (2005) Does Multimodal Analgesia with Acetaminophen, Nonsteroidal Antiinflammatory Drugs, or Selective Cyclooxygenase-2 Inhibitors and Patient-controlled Analgesia Morphine Offer Advantages over Morphine Alone?: Meta-analyses of Randomized Trials. Anesthesiology 103: 1296-1304. Link: https://bit.ly/3hEREdm

10. Ong CK, Seymour RA, Lirk P, Merry AF (2010) Combining paracetamo (acetaminophen) with nonsteroidal antiinflammatory drugs: a qualitative systematic review of analgesic efficacy for acute postoperative pain. Anesth Analg 110: 1170-1179. Link: https://bit.ly/2P1hs79

11. Platzer M, Likar R, Stettner H, Jost R, Wutti C, et al. (2011) Tonsillotomien and Adenotomien im Kindesalter. Studie zu postoperativen Schmerztherapie Tonsillotomy and adenotonsillectomy in childhood. Study on postoperative pain therapy. Anaesthesist 60: 625-632. Link: https://bit.ly/39B3a6A 
12. Cozowicz C, Poeran J, Zubizarreta N, Liu J, Weinstein SM, et al. (2019) Nonopioid analgesic modes of pain management are associated with reduced postoperative complications and resource utilisation: a retrospective study of obstructive sleep apnoea patients undergoing elective joint arthroplasty. $\mathrm{Br} \mathrm{J}$ Anaesth 122: 131-140. Link: https://bit.ly/2X21gH4
13. Choo S, Nogan S, Matrka L (2019) Postoperative Opioid Prescribing and Consumption Patterns after Tonsillectomy. Otolaryngology-Head and Neck Surgery 161: 960-966. Link: https://bit.ly/2X1H48t

\section{Discover a bigger Impact and Visibility of your article publication with}

\section{Peertechz Publications}

\section{Highlights}

* Signatory publisher of ORCID

* Signatory Publisher of DORA (San Francisco Declaration on Research Assessment)

* Articles archived in worlds' renowned service providers such as Portico, CNKI, AGRIS, TDNet, Base (Bielefeld University Library), CrossRef, Scilit, J-Gate etc.

* Journals indexed in ICMJE, SHERPA/ROMEO, Google Scholar etc.

* OAI-PMH (Open Archives Initiative Protocol for Metadata Harvesting)

* Dedicated Editorial Board for every journal

* Accurate and rapid peer-review process

* Increased citations of published articles through promotions

* Reduced timeline for article publication

Submit your articles and experience a new surge in publication services (https://www.peertechz.com/submission).

Peertechz journals wishes everlasting success in your every endeavours.

Copyright: () 2020 Reddy Bathula SS, et al. This is an open-access article distributed under the terms of the Creative Commons Attribution License, which permits unrestricted use, distribution, and reproduction in any medium, provided the original author and source are credited. 